\title{
Human immune deficiency virus among cervical cancer patients at Tikur Anbessa Specialized Hospital, Ethiopia: a cross sectional study
}

\author{
Mulugeta Wassie ${ }^{1}$, Beletech Fentie ${ }^{2}$ and Tseganesh Asefa ${ }^{1 *}$
}

\begin{abstract}
Background: The discrepancy in cervical cancer incidence between women with HIV and women without HIV is highest in low and middle-income countries. In Africa, cervical cancer is the most common cause of cancer death. As a result, HIV-infected women are 6 times more likely to develop cervical cancer than uninfected women. In addition, HIV is associated with several triggering factors for cervical cancer, including multiple sexual partners, early sexual debut, economic status and substance use.

Objective: To assess the prevalence and associated factors of HIV among cervical cancer patients at Tikur Anbessa Specialized Hospital, Addis Ababa, Ethiopia.

Methods: A cross sectional study was conducted among 1057 cervical cancer patients registered from January 1 , 2014 to December 31, 2018 at Oncology Center of Tikur Anbessa Specialized Hospital. A structured English version checklist was used to collect the data from patient charts. The pre coded data were entered in to EPI-data version 3.1 then exported to STATA version 14.0 for analysis. Both bivariable and multivariable regression analysis were carried out. Variables with $p$ value $<0.05$ in multivariable logistic regression were consider as significant predictors of the outcome variable.

Result: The prevalence of HIV among cervical cancer patients was 18.35\%. HIV among cervical cancer patients was significantly associated with age group 30-39 [AOR $=2.83 ; 95 \% \mathrm{Cl}(1.27,6.22)]$ and $40-49[\mathrm{AOR}=2.39 ; 95 \% \mathrm{Cl}(1.07$, 5.32)], employed $[\mathrm{AOR}=2.23 ; 95 \% \mathrm{Cl}(1.46,3.41)]$ and substance users $[\mathrm{AOR}=3.92 ; 95 \% \mathrm{Cl}(2.04,6.28)]$.

Conclusion: This study revealed that about $18 \%$ of cervical cancer patients were HIV seropositive. HIV seropositivity was significantly increased with 30-49 age group, employed and substance users. Authors recommended that it is better to screen all HIV seropositive patients for cervical cancer and give greater attention for women with cervical cancer in the age groups of 30-49 years, employed and substance users.
\end{abstract}

Keywords: HIV, Cervical cancer, TASH, Ethiopia

*Correspondence: tseganesh16@gmail.com

${ }^{1}$ Department of Medical Nursing, School of Nursing, College of Medicine and Health Sciences, University of Gondar, Gondar, Ethiopia

Full list of author information is available at the end of the article

\section{Introduction}

The prevalence of Human Immunodeficiency Virus (HIV) in women has suddenly increased since the early 1980s, when the diseases first entered public consciousness. Today an estimated 18 million women are living 
with HIV, in place of more than half of HIV-seropositive adults worldwide [1].

People living with HIV have been shown higher rates of HPV infection and more likely to be infected with high risk HPV and multiple HPV types than HIV negative individuals [2]. Women living with HIV have a greater incidence of Human Papilloma Virus (HPV) infection than do the general population. Numerous studies revealed that immune suppression with low $\mathrm{CD} 4$ counts predisposes women to high risk of HPV infection. HPV infection is the principal cause of oncogenic transformation and development of cervical intraepithelial neoplasia $(\mathrm{CIN})$, which are precursor lesions for cervical cancer [2, 3].

The discrepancy in cervical cancer incidence between women with HIV and without HIV is greatest in low and middle-income countries. In Africa, cervical cancer is the leading cause of cancer death, in which HIV-infected women are about 6 times more likely than uninfected women to develop cervical cancer death. In addition, HIV is associated with several enabling factors for cervical cancer, including multiple sexual partners, early sexual debut, economic status and substance use $[4,5]$.

Hence, HPV infection associated to HIV status is not the exclusive cause of cervical cancer. In addition to HIV associated HPV infection, other factors such as parity, smoking, diet, physical inactivity, sexual behavior, use of oral contraceptives, and aging are also contribute to the development of cervical cancer [6]. Therefore, this study aimed to assess the prevalence and associated factors of HIV among cervical cancer patients at TASH, Ethiopia.

\section{Method and materials}

\section{Study design, period and setting}

A cross sectional study was conducted at oncology center of TASH from March to April 2019. The hospital was established in 1972 and has more than 800 beds providing diagnostic and treatment service for about 400,000 patients per year. The oncology center at TASH is the largest referral site in the country, providing service for over 60,000 patients annually. It is the sole oncology referral and radiotherapy center in Ethiopia [7].

\section{Study population}

Medical records of women diagnosed with cervical cancer from January 1, 2014 to December 31, 2018 at oncology center of TASH were a study populations. Incomplete medical chart record and charts not found during a data collection were excluded.

\section{Sample size determination and sampling procedure}

All medical records of patients diagnosed with cervical cancer from January 1, 2014 to December 31, 2018 was the total sample size. A medical record of 1057 cases fulfilled the inclusion criteria. HIV status of the patient was the dependent variable, the patient HIV status was retrieved by trained medical staff from medical record chart and grouped HIV status as HIV-positive and HIVnegative. Sociodemographic characteristics such as age, marital status, resident, region, religion, occupation, substance use, number of children, stage, histopathology, anemia and treatment initiated were independent variables.

\section{Operational definition}

Substance use: Patients who used one, two or all of the three substances (cigarate, chat and alcohol) [8].

\section{Data collection tools and quality assurance}

A structured English version checklist was used to collect the data from patient charts. The checklist contains sociodemographic factors and HIV status of cervical cancer patients. Prior to data collection, training was provided for three data collectors having bachelors of degree in nursing and two supervisors having master's degree in clinical oncology nursing about the checklist and how to retrieve data from the medical record.

Pre-taste was conducted in $5 \%$ of the total sample size and the necessary modification was made on checklist accordingly. Furthermore, the data collection process was strictly supervised for completeness of the data before chart returned to the shelf.

\section{Data processing and analysis}

The pre coded data were entered in to EPI-data version 3.1 then exported to STATA version 14.0 for analysis. The descriptive statistics were used to describe the study population related to different characteristics. Binary logistic regression was employed for each variables with the outcome variable and those variables with $p<0.2$ were entered to multivariable analysis. Variables with $p$ value $<0.05$ in multivariable logistic regression were considered as a significant predictor of HIV among cervical cancer patients.

\section{Results}

Socio-demographic characteristics of study participants

In this study, 1057 cervical cancer patients were surveyed. Two hundred sixty two $(24.79 \%)$ of participants were under the age category $40-49$ years. Six hundred sixty five $(62.91 \%)$ of participants were married. Six hundred fourteen $(58.09 \%)$ of respondents came from urban area.

By region, 281 (26.58\%) and 280 (26.49) of participants were from Amhara and Addis Ababa region, respectively. Six hundred twenty nine $(59.51 \%)$ of 
respondents were orthodox Christianity followers in their religion. More than 905 (85.62\%) and 875 (82.78\%) of participants were unemployed and substance non user, respectively. Four hundred forty (41.63\%) of participants have more than three children. More than half (56.76\%) of participants were diagnosed at advanced (stage III \& IV). Closely half (51.18\%) and (49.20\%) of patients were anemic and received radiation therapy, respectively (Table 1 ).

\section{Prevalence of HIV among cervical cancer patients}

The overall prevalence of HIV among cervical cancer patients was $18.35 \%$ [95\% CI $(0.16,0.21)$ ] (Fig. 1). HIV prevalence was higher (27.84\%) among 40-49 age groups of cervical cancer patients. Nearly three fifth (57.73\%) of married cervical cancer patients were HIV positive. Closely two third (65.46\%) of cervical cancer patients live in urban area were HIV positive. More than two third (35.57\%) of cervical cancer patients from Addis Ababa were HIV positive. Whereas three fourth (74.74\%) of unemployed cervical cancer patients were HIV positive. About two third (63.40\%) and (61.86\%) of cervical cancer patients who did not use substances and diagnosed at advanced stage (III \& IV) were HIV positive, respectively. Nearly two fifth $(37.63 \%)$ and $(44.85 \%)$ of cervical cancer patients, who have three children and received a chemo/ RT were HIV positive. Three fourth $(76.8 \%)$ of anemic cervical cancer patients were HIV positive (Table 2).

\section{Predictors of HIV among cervical cancer patients}

Age, marital status, residence, region, occupation, substance use and number of children were fitted the outcome variable in the bivariable binary logistic regression at $p<0.2$. All variables with $p<0.2$ in the bi-variable analysis were included in the multivariable analysis. In multivariable analysis, three variables were found to be statistically significant at $p<0.05$ with $95 \%$ confidence interval. Accordingly, age, occupation and substance use demonstrated to have statically significant association with HIV positive among cervical cancer patients.

Cervical cancer patients aged 30-39 were 3 times $(\mathrm{AOR}=2.83 ; 95 \% \mathrm{CI}=1.27,6.32)$ more likely to be HIV seropositive than their counter parts. Correspondingly, cervical cancer patients aged 40-49 were two times $(\mathrm{AOR}=2.38 ; 95 \% \mathrm{CI}=1.07,5.32)$ more likely to be HIV seropositive than their counter parts. Employed cervical cancer patients were two times $(\mathrm{AOR}=2.24 ; 95 \%$ $\mathrm{CI}=1.46,3.44)$ more likely to be HIV seropositive than unemployed. Substance user cervical cancer patients were four times $(\mathrm{AOR}=3.93$; $95 \% \mathrm{CI}=2.64,5.83)$ more likely HIV seropositive than non-users (Table 3 ).
Table 1 Socio demographic and clinical characteristics of study participants at TASH, Ethiopia $(n=1057)$

\begin{tabular}{|c|c|c|c|}
\hline Characteristics & Code & Frequency & Percent \% \\
\hline \multirow[t]{5}{*}{ Age } & $<30$ & 92 & 8.70 \\
\hline & $30-39$ & 219 & 20.72 \\
\hline & $40-49$ & 262 & 24.79 \\
\hline & $50-59$ & 245 & 23.28 \\
\hline & $>=60$ & 239 & 22.61 \\
\hline \multirow[t]{2}{*}{ Marital status } & Single & 392 & 37.09 \\
\hline & Married & 665 & 62.91 \\
\hline \multirow[t]{2}{*}{ Residence } & Urban & 614 & 58.09 \\
\hline & Rural & 443 & 41.91 \\
\hline \multirow[t]{6}{*}{ Region } & Amhara & 281 & 26.58 \\
\hline & Oromia & 341 & 32.26 \\
\hline & Tigray & 30 & 2.84 \\
\hline & SNNP & 95 & 8.99 \\
\hline & Addis Ababa & 280 & 26.49 \\
\hline & Others & 30 & 2.84 \\
\hline \multirow[t]{4}{*}{ Religion } & Orthodox & 629 & 59.51 \\
\hline & Muslim & 201 & 19.02 \\
\hline & Protestant & 212 & 20.06 \\
\hline & Other & 15 & 1.42 \\
\hline \multirow[t]{2}{*}{ Occupation } & Unemployed & 905 & 85.62 \\
\hline & Employed & 152 & 14.38 \\
\hline \multirow[t]{2}{*}{ Substance use } & User & 182 & 17.22 \\
\hline & None user & 875 & 82.78 \\
\hline \multirow[t]{5}{*}{ Number of children } & No child & 40 & 3.78 \\
\hline & One child & 69 & 6.53 \\
\hline & Two child & 147 & 13.91 \\
\hline & Three child & 361 & 34.15 \\
\hline & $>3$ child & 440 & 41.63 \\
\hline \multirow[t]{2}{*}{ Stage } & Stage | \& || & 457 & 43.24 \\
\hline & Stage III \& IV & 600 & 56.76 \\
\hline \multirow[t]{2}{*}{ Histopathology } & $\begin{array}{l}\text { Squamous cell carci- } \\
\text { noma }\end{array}$ & 959 & 90.73 \\
\hline & Adenocarcinoma & 98 & 9.27 \\
\hline \multirow[t]{2}{*}{ Anemia } & Yes & 541 & 51.18 \\
\hline & No & 516 & 48.82 \\
\hline \multirow[t]{6}{*}{ Treatment initiated } & Surgery and chemo & 17 & 1.61 \\
\hline & Chemo & 19 & 1.80 \\
\hline & Radiotherapy & 520 & 49.20 \\
\hline & Chemo and RT & 375 & 35.48 \\
\hline & Surgery and RT & 111 & 10.50 \\
\hline & Chemo + surgery + RT & 15 & 1.42 \\
\hline
\end{tabular}

\section{Discussion}

The current study aimed to assess the prevalence and associated factors of HIV among cervical cancer patients. In this study the prevalence of HIV among cervical cancer patient was about $18 \%$. This prevalence is in line with the study in KwaZulu-Natal, South Africa 


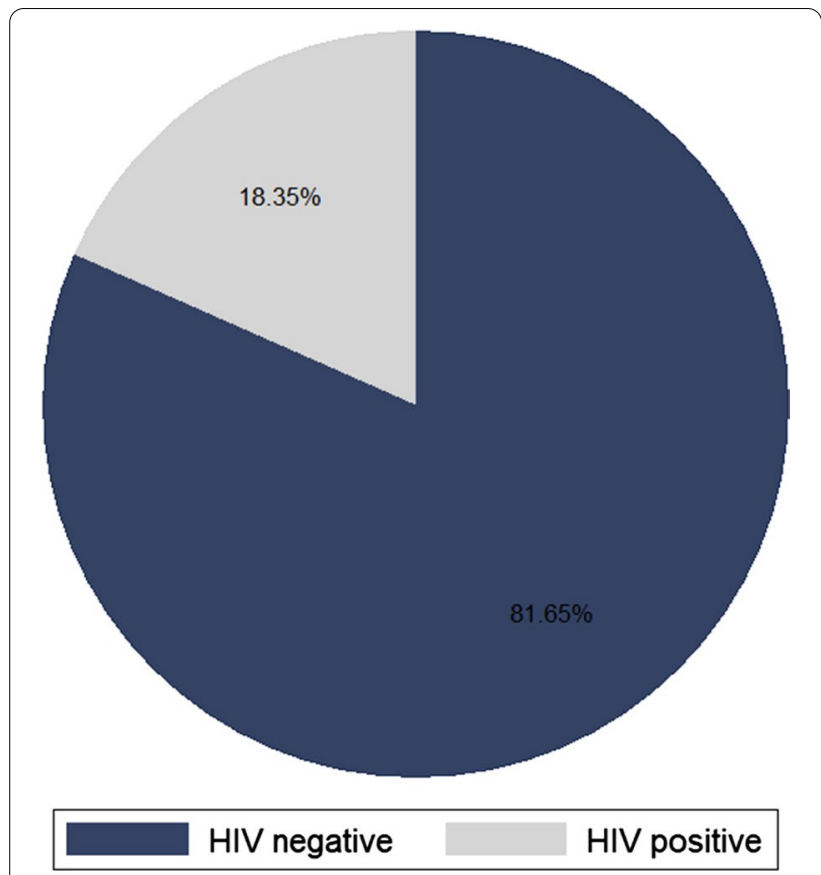

Fig. 1 Prevalence of HIV among cervical cancer patients at TASH, Ethiopia $(n=1057)$

with the prevalence of $21 \%$ [9]. On the other hand, the result of this study is higher than the studies conducted in Ethiopia 13.3\% [10], South Africa 7.2\% [11], Nigeria 6\%[12], Kenya 1.5\% [13] and Guinea 2.1\% [14]. This might be due to variations in the sample size, study period, study area and population.

In the current study, the women within the age group of 30-39 and 40-49 years were about three times and two times more HIV seropositive than those age with age group below 30 years, respectively. This finding is similar with the study done in Ivory Coast [15], Tanzania [16] and Kenya [17]. This might be women with age 30-49 years a time which become sexually active and may have a repeated unprotected sexual exposure that my contribute to increase the rate of HIV prevalence [18]

Substance users presented with HIV seropositive status about four times more than non-user cervical cancer patients. This finding comparable with studies in Brazil [19], USA [20] and South Africa [21]. This could be due to the fact that substance use has been a potential to divert a person attitude towards sexual risk behavior such as unprotected sex and multiple sexual partners [22]. On the other hand, it reduce the immune system ability to fight against infections like HPV in addition it introduce chemicals which might be carcinogens to body [23]. Correspondingly, other studies revealed HIV infection itself as a risk factor for cervical cancer. All this conditions
Table 2 Prevalence of HIV among cervical cancer patients at TASH, Ethiopia $(n=1057)$

\begin{tabular}{|c|c|c|}
\hline \multirow[t]{2}{*}{ Characteristics } & \multicolumn{2}{|l|}{ HIV } \\
\hline & Positive N (\%) & Negative $\mathbf{N}(\%)$ \\
\hline \multicolumn{3}{|l|}{ Age } \\
\hline$<30$ & $9(4.64)$ & $83(9.62)$ \\
\hline $30-39$ & $52(26.80)$ & $167(19.35)$ \\
\hline $40-49$ & $54(27.84)$ & $208(24.10)$ \\
\hline $50-59$ & $46(23.71)$ & 199 (23.06) \\
\hline$>=60$ & $33(17.01)$ & $206(23.87)$ \\
\hline \multicolumn{3}{|l|}{ Marital status } \\
\hline Single & $82(42.27)$ & $310(35.92)$ \\
\hline Married & $112(57.73)$ & $553(64.08)$ \\
\hline \multicolumn{3}{|l|}{ Residence } \\
\hline Urban & $127(65.46)$ & $487(56.43)$ \\
\hline Rural & $67(34.54)$ & $376(43.57)$ \\
\hline \multicolumn{3}{|l|}{ Region } \\
\hline Amhara & $49(25.26)$ & $232(26.88)$ \\
\hline Oromia & $44(22.68)$ & $297(34.41)$ \\
\hline Tigray & $7(3.61)$ & $23(2.67)$ \\
\hline SNNP & $22(11.34)$ & $73(8.46)$ \\
\hline Addis Ababa & $69(35.57)$ & $211(24.45)$ \\
\hline Others & $3(1.55)$ & $27(3.13)$ \\
\hline \multicolumn{3}{|l|}{ Religion } \\
\hline Orthodox & $113(58.25)$ & $516(59.79)$ \\
\hline Muslim & $31(15.98)$ & $170(19.70)$ \\
\hline Protestant & $49(25.26)$ & $163(18.89)$ \\
\hline Other & $1(0.52)$ & $14(1.62)$ \\
\hline \multicolumn{3}{|l|}{ Occupation } \\
\hline Unemployed & $145(74.74)$ & $760(88.06)$ \\
\hline Employed & $49(25.26)$ & $103(11.94)$ \\
\hline \multicolumn{3}{|l|}{ Substance use } \\
\hline User & $71(36.60)$ & $111(12.86)$ \\
\hline None user & $123(63.40)$ & $752(87.14)$ \\
\hline \multicolumn{3}{|l|}{ Number of children } \\
\hline No child & $10(5.15)$ & $30(3.48)$ \\
\hline One child & $25(12.89)$ & $44(5.10)$ \\
\hline Two child & $35(18.04)$ & $112(12.98)$ \\
\hline Three child & $73(37.63)$ & $288(33.37)$ \\
\hline$>3$ child & $51(26.29)$ & $389(45.08)$ \\
\hline \multicolumn{3}{|l|}{ Stage } \\
\hline Stage I\&\| & $74(38.14)$ & $383(44.38)$ \\
\hline Stage III \&IV & $120(61.86)$ & $480(55.62)$ \\
\hline \multicolumn{3}{|l|}{ Histopathology } \\
\hline Squamous cell carcinoma & $181(93.30)$ & $778(90.15)$ \\
\hline Adenocarcinoma & $13(6.70)$ & $85(9.85)$ \\
\hline \multicolumn{3}{|l|}{ Anemia } \\
\hline Yes & $149(76.8)$ & $392(45.42)$ \\
\hline No & $45(23.20)$ & $471(54.58)$ \\
\hline \multicolumn{3}{|l|}{ Treatment initiated } \\
\hline Surgery and chemo & $5(2.58)$ & $12(1.39)$ \\
\hline
\end{tabular}


Table 2 (continued)

\begin{tabular}{lll}
\hline Characteristics & \multicolumn{1}{l}{ HIV } \\
\cline { 2 - 3 } & Positive N (\%) & Negative N (\%) \\
\hline Chemo & $1(0.52)$ & $18(2.09)$ \\
Radiotherapy & $79(40.72)$ & $441(51.10)$ \\
Chemo and RT & $87(44.85)$ & $288(33.37)$ \\
Surgery and RT & $21(10.82)$ & $90(10.43)$ \\
Chemo + surgery + RT & $1(0.52)$ & $14(1.62)$ \\
\hline
\end{tabular}

might predispose individuals to HPV infection and facilitate cervical cancer development.

Employed cervical cancer patients in the current study presented with HIV seropositive status about two times higher than those unemployed. This finding is supported by the study in Brazil [24]. Women who works in hazardous environment without protective equipment could contribute to the increment of HIV prevalence for the employed patients [25]. In addition other study stated that HIV infection is associated with some occupations like health care workers like surgeons, anesthetist, and physicians engaged in invasive procedures [26]. This could indicate that employed in unsafe work environment might be associated with HIV infection.

\section{Conclusion}

This study revealed that about $18 \%$ of cervical cancer patients were HIV seropositive. HIV sero positivity significantly increased with 30-49 age group, employed and

Table 3 Result of bivariable and multivariable binary logistic regression analysis of cervical cancer patients at TASH, Ethiopia $(n=1057)$

\begin{tabular}{|c|c|c|c|c|c|}
\hline Characteristics & $\begin{array}{l}\text { HIV positive } \\
\mathrm{N}(\%)\end{array}$ & $\begin{array}{l}\text { HIV negative } \\
\mathrm{N}(\%)\end{array}$ & COR $(95 \% \mathrm{CI})$ & AOR (95\% CI) & $P$ value \\
\hline \multicolumn{6}{|l|}{ Age } \\
\hline$<30$ & $9(4.64)$ & $83(9.62)$ & 1 & 1 & \\
\hline $30-39$ & $52(26.80)$ & 167 (19.35) & $2.87[1.34,6.11]$ & $2.83[1.27,6.32]$ & $0.011^{*}$ \\
\hline $40-49$ & $54(27.84)$ & $208(24.10)$ & $2.39[1.13,5.07]$ & $2.38[1.07,5.32]$ & $0.034^{*}$ \\
\hline $50-59$ & $46(23.71)$ & 199 (23.06) & $2.13[0.99,4.55]$ & $2.13[0.94,4.84]$ & 0.070 \\
\hline$>=60$ & $33(17.01)$ & 206 (23.87) & $1.48[0.68,3.22]$ & $1.37[0.59,3.17]$ & 0.457 \\
\hline \multicolumn{6}{|l|}{ Marital status } \\
\hline Single & $82(42.27)$ & 310 (35.92) & $1.31[0.95,1.79]$ & $1.35[0.95,1.92]$ & 0.087 \\
\hline Married & $112(57.73)$ & $553(64.08)$ & 1 & 1 & \\
\hline \multicolumn{6}{|l|}{ Residence } \\
\hline Urban & $127(65.46)$ & $487(56.43)$ & 1 & 1 & \\
\hline Rural & $67(34.54)$ & $376(43.57)$ & $0.68[0.49,0.94]$ & $1.02[0.67,1.55]$ & 0.929 \\
\hline \multicolumn{6}{|l|}{ Region } \\
\hline Amhara & $49(25.26)$ & $232(26.88)$ & 1 & 1 & \\
\hline Oromia & $44(22.68)$ & $297(34.41)$ & $0.70[0.45,1.09]$ & $0.74[0.45,1.18]$ & 0.209 \\
\hline Tigray & $7(3.61)$ & $23(2.67)$ & $1.44[0.58,3.55]$ & $1.70[0.64,4.49]$ & 0.284 \\
\hline SNNP & $22(11.34)$ & $73(8.46)$ & $1.43[0,81,2.52]$ & $1.76[0.95,3.26]$ & 0.071 \\
\hline Addis Ababa & $69(35.57)$ & $211(24.45)$ & $1.55[1.03,2.34]$ & $1.47[0.90,2.41]$ & 0.121 \\
\hline Others & $3(1.55)$ & $27(3.13)$ & $0.53[0.15,1.80]$ & $0.49[0.14,1.79]$ & 0.286 \\
\hline \multicolumn{6}{|l|}{ Occupation } \\
\hline Unemployed & $145(74.74)$ & $760(88.06)$ & 1 & 1 & \\
\hline Employed & $49(25.26)$ & 103 (11.94) & $2.49[1.69,3.66]$ & $2.24[1.46,3.44]$ & $0.000^{*}$ \\
\hline \multicolumn{6}{|l|}{ Substance use } \\
\hline User & $71(36.60)$ & $111(12.86)$ & $3.91[2.75,5.57]$ & $3.93[2.64,5.83]$ & $0.000^{*}$ \\
\hline None user & $123(63.40)$ & $752(87.14)$ & 1 & & \\
\hline \multicolumn{6}{|c|}{ Number of children } \\
\hline No child & $10(5.15)$ & $30(3.48)$ & 1 & 1 & \\
\hline One child & $25(12.89)$ & $44(5.10)$ & $1.70[0.72,4.06]$ & $2.22[0.83,5.91]$ & 0.111 \\
\hline Two child & $35(18.04)$ & $112(12.98)$ & $0.94[0.42,2.11]$ & $1.38[0.56,3.44]$ & 0.485 \\
\hline Three child & $73(37.63)$ & $288(33.37)$ & $0.76[0.35,1.63]$ & $1.01[0.42,2.43]$ & 0.973 \\
\hline$>3$ child & $51(26.29)$ & $389(45.08)$ & $0.39[0.18,0.85]$ & $0.81[0.33,1.97]$ & 0.644 \\
\hline
\end{tabular}

$\mathrm{Cl}$ : confidence interval, * significant at p-value less than 0.05 
substance users. Authors recommend that it is better to screen all HIV seropositive for cervical cancer and give greater attention for women with cervical cancer in the age groups of 30-49 years employed and substance users.

\section{Abbreviations}

AOR: Adjusted odd ratio; HIV: Human immunodeficiency virus; HPV: Human papilloma virus; OR: Odd ratio; TASH: Tikur Anbessa Specialized Hospital.

\section{Acknowledgements}

Our genuine thank was goes to Addis Ababa University for providing ethical clearance. Also, the authors would like to acknowledge the hospital director and data collectors for their collaboration during data collection.

\section{Authors' contributions}

TA performed statistical analysis and draft the manuscript. MW and BF participated in designing the study, analysis, reviewing and editing the final manuscript and contributed to the discussion. MW, BF and TA carried out the conception, designing the study data collection and revising the manuscript critically with valid inputs. All authors read and approved the final form of the manuscript.

\section{Funding}

The authors were not funded for this work.

\section{Availability of data and materials}

The datasets used in this study are available upon of correspondent author.

\section{Declarations}

\section{Ethical approval and consent to participants}

Ethical clearance was obtained from Institutional Review Board (IRB) of School of Nursing and Midwifery, Addis Ababa University. A permission letter was written from School of Nursing and Midwifery to oncology center of Tikur Anbessa Specialized Hospital. Then, the cancer center chief administrator allowed to collect the data from the cervical cancer patients' medical records. The study was conducted without individual patients' informed consent since it relies on chart review. Informed consent of the patients was waived off by the cancer administrative officials of Tikur Anbessa Specialized Hospital, Ethiopia, as the data intended to collect on the patient's charts since the individual patients could not be found during the data collection period. Confidentiality was maintained by avoiding registration of personal identifiers like name, medical record numbers and also no raw data was given for any other person. All methods were performed in accordance with the relevant guidelines and regulations.

\section{Consent for publication}

Not applicable.

\section{Competing interests}

The authors declare no competing interests.

\section{Author details}

${ }^{1}$ Department of Medical Nursing, School of Nursing, College of Medicine and Health Sciences, University of Gondar, Gondar, Ethiopia. ${ }^{2}$ Department of Pediatrics and Child Health Nursing, School of Nursing, College of Medicine and Health Sciences, University of Gondar, Gondar, Ethiopia.

Received: 25 March 2021 Accepted: 31 July 2021

Published online: 09 August 2021

\section{References}

1. Blumenthal S. amfAR, The Foundation for AIDS Research.
2. Palefsky JM. HPV-associated anal and cervical cancers in HIV-infected individuals: incidence and prevention in the antiretroviral therapy era. Curr Opin HIV AIDS. 2017;12(1):26.

3. McDonald AC, et al. Distribution of human papillomavirus genotypes among HIV-positive and HIV-negative women in Cape Town South Africa. Front Oncol. 2014;4:48.

4. Ghebre RG, et al. Cervical cancer control in HIV-infected women: past, present and future. Gynecol Oncol Rep. 2017;21:101-8.

5. Dryden-Peterson S, et al. HIV infection and survival among women with cervical cancer. J Clin Oncol. 2016;34(31):3749.

6. Thun MJ, et al. The global burden of cancer: priorities for prevention. Carcinogenesis. 2010;31(1):100-10.

7. Sibhat SG, et al. Health-related quality of life and its predictors among patients with breast cancer at Tikur Anbessa Specialized Hospital, Addis Ababa, Ethiopia. Health Qual Life Outcomes. 2019;17(1):1-10.

8. WHO. Promoting mental health: concepts, emerging evidence, practice: a report of the World Health Organization, Department of Mental Health and Substance Abuse in collaboration with the Victorian Health Promotion Foundation and the University of Melbourne. World Health Organization; 2005

9. Moodley M, Moodley J, Kleinschmidt I. Invasive cervical cancer and human immunodeficiency virus (HIV) infection: a South African perspective. Int J Gynecol Cancer. 2001;11(3):194.

10. Lema K, Negash S, Yusuf L. Sero-prevalence of HIV among patients with cervical cancer managed at the Tikur Anbassa Hospital Addis Ababa, Ethiopia. East Afr Med J. 2018;95(4):1438-51.

11. Moodley M, Mould S. Invasive cervical cancer and human immunodeficiency virus (HIV) infection in KwaZulu-Natal, South Africa. J Obstet Gynaecol. 2005;25(7):706-10.

12. Ocheni S, Aken'Ova Y. Association between HIV/AIDS and malignancies in a Nigerian tertiary institution. West Afr J Med. 2004;23(2):151-5.

13. Rogo K. Human immunodeficiency virus seroprevalence among cervical cancer patients. Gynecol Oncol. 1990;37(1):87-92.

14. Traore $B$, et al. The prevalence of HIV in cancer patients at the surgical oncology unit of Donka University Hospital of Conakry (Guinea). J Cancer Epidemiol. 2010;2015:1.

15. Adjorlolo-Johnson $\mathrm{G}$, et al. Assessing the relationship between HIV infection and cervical cancer in Cote d'Ivoire: a case-control study. BMC Infect Dis. 2010;10(1):1-8.

16. Chambuso R., E. Kaambo, and S. Stephan, Observed age difference and clinical characteristics of invasive cervical cancer patients in tanzania; a comparison between HIV-positive and HIV-negative women. J Neoplasm, 2017. 2(3)

17. Gichangi PB, et al. Impact of HIV infection on invasive cervical cancer in Kenyan women. AIDS. 2003;17(13):1963-8.

18. Richards SD, et al. Cervical cancer screening among transactional female sex workers in the Dominican Republic. Int J STD AIDS. 2018;29(12):1204-14.

19. Boldrini NAT, et al. Sexually transmitted infections among women living with HIV in a Brazilian city. Brazil J Infect Diseases. 2021;25(1):101044.

20. Sims OT, et al. A descriptive analysis of concurrent alcohol and substance use among patients living with HIV/HCV co-infection. Soc Work Health Care. 2020;59(7):525-41.

21. Scheibe A, et al. Hepatitis B, hepatitis $C$ and HIV prevalence and related sexual and substance use risk practices among key populations who access HIV prevention, treatment and related services in South Africa: findings from a seven-city cross-sectional survey (2017). BMC Infect Dis. 2020;20(1):1-15.

22. Carrico AW, et al. Affect regulation, stimulant use, and viral load among HIV-positive persons on anti-retroviral therapy. Psychosom Med. 2007;69(8):785-92.

23. Amoakwa K, et al. Risk factors for developing active tuberculosis after the treatment of latent tuberculosis in adults infected with human immunodeficiency virus. In Open forum infectious diseases. 2015. Oxford University Press.

24. Tabalipa MdM, et al. Informação sobre ocupação em registros hospitalares de câncer no estado do Rio de Janeiro. Cad. saúde colet.,(Rio J.), 2011.

25. Brito-Marcelino A, et al. Cervical cancer related to occupational risk factors. Revista Brasileira de Medicina do Trabalho. 2020;18(1):103. 
26. Wyżgowski P, et al. Occupational HIV risk for health care workers: risk factor and the risk of infection in the course of professional activities. Ther Clin Risk Manag. 2016;12:989.

\section{Publisher's Note}

Springer Nature remains neutral with regard to jurisdictional claims in published maps and institutional affiliations.

- fast, convenient online submission

- thorough peer review by experienced researchers in your field

- rapid publication on acceptance

- support for research data, including large and complex data types

- gold Open Access which fosters wider collaboration and increased citations

- maximum visibility for your research: over $100 \mathrm{M}$ website views per year

At BMC, research is always in progress.

Learn more biomedcentral.com/submissions 